\title{
Teachers' Beliefs about the Discipline of Mathematics and the Use of Technology in the Classroom
}

\author{
Morten Misfeldt \\ Aalborg University DENMARK \\ Uffe Thomas Jankvist \\ Aarhus University DENMARK \\ Mario Sánchez Aguilar \\ National Polytechnic Institute. MEXICO
}

-Received 25 October $2015 \bullet$ Revised 15 January $2016 \bullet$ Accepted 27 January 2016

In the article, three Danish secondary level mathematics teachers' beliefs about the use of technological tools in the teaching of mathematics and their beliefs about mathematics as a scientific discipline are identified and classified - and the process also aspects of their beliefs about the teaching and learning of mathematics. The potential relationships between these sets of beliefs are also explored. Results show that the teachers not only manifest different beliefs about the use of technology and mathematics as a discipline, but that one set of beliefs can influence the other set of beliefs. The article concludes with a discussion of the research findings and their validity as well as their implications for both practice and research in mathematics education.

Keywords: mathematics teachers' beliefs, beliefs about mathematics as a discipline, beliefs about use of technology, lever potential, blackboxing

\section{INTRODUCTION}

The integration of technological tools (computers, calculators, mobile devices, etc.), and in particular how such technological tools are used in the mathematics classroom, to a large extent depend on teachers (Thomas \& Palmer, 2014). It is known that one of the factors influencing teachers' use of digital technologies is their pedagogical beliefs (Goos, 2014); for example, teachers' beliefs about the efficacy of computer use in mathematics (Forgasz, 2002), and their beliefs about the nature of teaching and learning of mathematics (Thomas \& Palmer, 2014; Walen, Williams \& Garner, 2003). But what about teachers' beliefs about the nature of mathematics as a (scientific) discipline? Do they affect the way teachers perceive technological artifacts as tools for mathematics teaching and learning? And if so, then how?

Correspondence: Morten Misfeldt,

Aalborg University, Department of Learning and Philosophy, AC Meyers Vænge 15.

2450 Copenhagen DENMARK

E-mail: Misfeldt@learning.aau.dk

doi: 10.29333/iejme/341 
Beliefs about mathematics as a (scientific) discipline (Jankvist, 2015) are different in nature from what in the literature is usually referred to as beliefs about mathematics and/or beliefs about mathematics as a taught school subject (e.g. Op't Eynde, de Corte \& Verschaffel, 2002), as the former also includes beliefs about how mathematics has come into being, if mathematics is discovered or invented, if mathematics can become obsolete, etc. (for an elaborated discussion, please refer to Jankvist, 2015). The potential influence of this kind of beliefs in the way mathematics teachers perceive and adopt the use of technological tools for teaching is an under-researched topic in the field of mathematics education. However, we find that it is an issue that deserves attention, the reason being that it can expand our knowledge about the factors preventing or promoting the incorporation of technological tools in the mathematics classroom. Hence, in this article we explore the potential relationships between the beliefs that teachers have regarding mathematics as a scientific discipline, and their beliefs about the use of technological tools in the teaching and learning of mathematics. In doing so we necessarily also come to touch upon and uncover aspects of teachers' beliefs about the teaching and learning of mathematic. Hence, the study deals with these along the way too. To carry out the exploration we rely on an analysis of questionnaires and interviews conducted with a group of three teachers in Danish secondary school, where use of ICT in the mathematics lessons is now compulsory. More precisely, we seek to investigate the interaction of teacher beliefs structures by addressing the following three questions:

1. What are the three teachers' beliefs about use of technology in the teaching and learning of mathematics?

2. What are the three teachers' beliefs about mathematics as a discipline?

3. What are the relationships between the teachers' beliefs about use of technology and their beliefs about mathematics as a discipline, e.g. does their technology-related beliefs seem to be derived from or affect their mathematicsrelated beliefs and vice versa?

The article is structured as follows. First we provide the setting and background for the study and data collection. Next we describe the theoretical constructs to be applied in analyzing both sets of the teacher beliefs. Following this, we account for the methodology of the study (this is touched upon again in the discussion section). Then we present and analyze the data; first a section on the three teachers' technology-related beliefs; second a section on their beliefs about the discipline of mathematics; and third a section characterizing the beliefs systems for each of the three teachers. These sections to some extent aim at answering research questions 1 and 2. In the concluding discussion section, which is next, we aim at answering research question 3 as well as discussing the validity of the results and methodology of the study. Finally, we provide a section on potential consequences of these findings for mathematics education and mathematics education research.

\section{SETTING AND BACKGROUND}

The data that we build upon in this article originate from a large scale intervention project in Danish primary and lower secondary school. The project is one of five projects initiated by the Danish Ministry of Education in order to leverage the use of technology in the public school system. ${ }^{1}$ In particular, the project addresses development of ICT didactics, understood as methods, knowledge, and shared understandings of how to best bring technology into the teaching of core topics. The specific goal of the intervention is "to experiment with innovative forms of learning and enhance teachers' competencies in developing synergies between

\footnotetext{
${ }^{1}$ See www.demonstrationsskoler.dk for descriptions of the five projects.
} 
disciplinary knowledge, pedagogical knowledge and knowledge about ICT in order to develop a didactic language for the integration of ICT and digital resources among teachers" (Georgsen et al., 2014, p. 5, our translation). Inspired by Fullan (1991), these interventions have been conducted in four phases. In the first phase, referred to as staging, the mutual expectations were clarified and the overall structure is matched to the schools' local conditions and policies. In the second phase, initiation, the consultant provided input and inspiration to the group of teachers. In the third phase, the implementation, the actual development and testing of educational activities were conducted. Finally, in the fourth phase, institutionalization, the developed processes, insights, and routines were to be anchored in the organization.

The background of the study in this article is an intervention conducted with a group of four mathematics teachers at a school. The intervention consisted of seven meetings with an external consultant, and three instances of supervising/observing each other's teaching (the consultant did not observe). These meetings were distributed during the four phases. The specific intervention began in April, 2014, and ended in November same year with an intention of continuing the changed practices throughout the rest of the school year (i.e. until June). Throughout the intervention and after, we have been in contact with the consultant (a mathematics teacher educator) involved with this group of four mathematics teachers. He described that the intervention was conducted in a positive spirit, but that the project's focus on inquiry based approaches and technology use was quite foreign terrain to the teachers at the beginning. He said that the focus on innovative teaching at first did not seem to create any images or resonance with this group of teachers. But despite the fact that the teachers were unfamiliar with the approaches, they did, according to the consultant, end up changing their practice in a number of ways aligned with the project. Three of the four teachers in this group were able to participate in our data collection. These three teachers (all female) were experienced mathematics teachers, at either primary and secondary level, each with more than a decade of experience from practice. We shall provide a description of the three teachers later, but for now we turn our attention to the theoretical constructs applied in our study of these teachers.

\section{THE ORETICAL CONSTRUCTS RELATED TO TEACHERS' BELIEFS}

The literature reviewed and the constructs presented in this section stress the importance of teachers' beliefs about (1) the use and role of technology in teaching, and (2) the nature of mathematics as a discipline. Both sets of beliefs have the potential to shape teachers' practice and, as a consequence, the mathematical education of their students. Along the way we also touch upon connections between these beliefs and teachers' beliefs about the teaching and learning of mathematics. Before we enter into teachers' beliefs related to mathematics as a discipline and technology use, respectively, we briefly introduce the notion of teachers' beliefs in general.

\section{ON TEACHERS' BELIEFS IN GENERAL}

Teachers' beliefs about mathematics and its teaching and learning have been connected to teachers' intentions of practice and their actual teaching practices (e.g. Liljedahl, 2009). Philipp (2007, p. 259) defines teachers' beliefs as "Psychologically held understandings, premises, or propositions about the world that are thought to be true." A belief is an "entity" that stands in relation to other "entities", e.g. attitude, emotion, knowledge, etc. (Thompson, 1992). However, according to Philipp's literature review, beliefs are usually regarded as a more cognitive element than emotions and attitudes, and are therefore harder to change these. But as evidenced 
from several research reports, beliefs can be modified (Gill, Ashton, \& Algina, 2004; Swan, 2007; Wilkins \& Brand, 2004). Generally, change in beliefs is attributed to the structure of the beliefs, particularly their psychologically held strength and centrality, meaning that some beliefs are characterized as central beliefs, i.e. beliefs upon which other beliefs - more peripheral beliefs - are founded and derived (Green, 1971). Beliefs in general, and in particular central beliefs, may be regarded as "lenses through which one looks when interpreting the world" (Philipp, 2007, p. 258). This is to say, beliefs act as filters that affect what one sees, and people generally have difficulties seeing what they do not already believe (Pajares, 1992). The different types of beliefs, e.g. central and peripheral beliefs, and the relationships between them, are usually referred to as a beliefs system (Green,1971). Hence, a beliefs system is a structure composed of several collections of beliefs having different psychological strength, where the strongest beliefs collections have a central position in the system, and thus also are the hardest to change. A beliefs system can also include beliefs held in isolated clusters, which enables contradictory beliefs to coexist in the same system (Green, 1971). Related to this is Green's distinction between evidentially held and non-evidentially held beliefs, since the latter may allow contradictory beliefs to coexist in a system. More precisely, some beliefs may be merely a matter of taste and thus be integrated into the system as long as they make sense for the individual; in other words, some beliefs are supported and integrated into the system by completely subjective criteria (Leatham, 2006).

As stated by Philipp (2007, p. 259), "beliefs, unlike knowledge, may be held with varying degrees of conviction and are not consensual." The coexistence of contradictory beliefs within a beliefs system has important methodological implications. Leatham (2006) indicates how seemingly contradictory beliefs might appear, but the individual holding such beliefs is often able to solve the conflict and assimilate the beliefs into the system. To the observer this may seem illogical or unreasonable, but within the individual's system the beliefs may still appear with some internal consistency. In Leatham's (2006, p. 95) words: "our incredulity does not diminish another's coherence." As for the connection between beliefs and knowledge, this is widely discussed in the literature. Furinghetti and Pehkonen (2002, p. 43) propose to distinguish between two different kinds of knowledge: "objective (official) knowledge that is accepted by a community and subjective (personal) knowledge that is not necessarily subject to an outsider's evaluation". They argue that beliefs should be considered as belonging to the subjective knowledge.

\section{TEACHERS' BELIEFS ABOUT USE OF TECHNOLOGY IN MATHEMATICS EDUCATION}

There is research evidence showing a connection between teachers' beliefs about the teaching and learning of mathematics and the adoption and use of technological tools for its teaching. For instance, in a study involving thirty calculus teachers with different levels of experience (pre-service teachers, teachers trainees, and experienced teachers), Erens and Eichler (2015) identified two general teachers' beliefs systems, which they called "the old school" and "technology supporter", and relate such beliefs systems to teachers' ways of integrating graphing and computeralgebra technology in their calculus teaching. Teachers who themselves claim to belong to "the old school" expressed serious doubts and resistance towards the use of technology in their mathematics teaching. The researchers attribute these doubts and resistance to deeply-rooted objections in the teachers' beliefs system, such as the conviction that students need to fully understand mathematical ideas before 
making use of technology. On the other hand, teachers classified as "technology supporters" use technology to foster a problem-oriented approach to teaching calculus. These teachers perceive several benefits of using technology, such as making the class more dynamic and effective - as compared to a chalk and blackboard approach - and favour the visualization and multiple representations of mathematical concepts.

In a different study, Tharp, Fitzsimmons, and Ayers (1997) found that teachers holding a more rule-based view of learning mathematics typically do not believe the use of technology (graphic calculators) to enhance instruction, whereas teachers with less rule-based views of the subject were more likely to see technology as an integral part of the instruction. Hanzsek-Brill (1997, cited from Leatham, 2007) expanded the observation by locating three positions among teachers who use technology in their teaching: (1) teachers with exploratory beliefs believe that technology can and should be used to teach and learn mathematical concepts and procedures; (2) teachers with post-mastery beliefs find that technology should not be introduced until after the students have mastered concepts and procedures by hand; and (3) teachers with pre-mastery beliefs find themselves located somewhere in between exploration and post-mastery. The majority of teachers studied by Fleener (1995) as well as Walen, Williams, and Garner (2003) possessed postmastery beliefs. Walen et al. (2003) articulate the post-mastery beliefs of their teachers to be "that basic arithmetic skills must be learned, that the task of their future students was not to do mathematics, but to learn mathematics" (p. 459).

\begin{tabular}{|c|c|c|c|}
\hline \multicolumn{2}{|c|}{ "The old school" } & \multicolumn{2}{|c|}{ “Technology supporters" } \\
\hline $\begin{array}{l}\text { No technology } \\
\text { beliefs }\end{array}$ & $\begin{array}{l}\text { Post-mastery } \\
\text { beliefs }\end{array}$ & $\begin{array}{l}\text { Pre-mastery } \\
\text { beliefs }\end{array}$ & $\begin{array}{l}\text { Exploratory } \\
\text { beliefs }\end{array}$ \\
\hline
\end{tabular}

Figure 1. Schematic of teacher's technology-related beliefs.

Figure 1 illustrates the connections between the distinction by Erens and Eichler (2015) and that of Hanzsek-Brill (1997). In this figure, "the old school" teachers range from having no technology beliefs, i.e. that technology ought not be used in the teaching and learning of mathematics, to having post-mastery beliefs. The "technology supporters" cover a continuum from post-mastery over pre-mastery to exploratory beliefs regarding the use and role of technology in mathematics teaching and learning.

A few constructs from technology literature that are relevant in relation to teachers' technology-related beliefs are those of lever potential (Dreyfus, 1994; Winsløw, 2003) and blackboxing (e.g. Nabb, 2010). In a technology environment, it is possible to focus the students' attention on the activity deemed most relevant, e.g. students spend less time on writing things neatly down, drawing geometrical figures and making tables by hand, etc. In this sense, technology used as a lever potential can save time, increase the mathematical activity of each student, and focus the activities in the classroom (Dreyfus, 1994). But this lever potential can also work by outsourcing - or blackboxing - certain of the mathematical processes, and thus directing attention away from these processes. Whether or not such use of technology is deemed allowable by a teacher may be quite dependant on the teacher's technology-related beliefs. For example, a teacher holding post-mastery beliefs may be expected to be more sceptical towards such blackboxing of mathematical processes, while a teacher holding exploratory beliefs may allow it to 
a higher extent. Blackboxing, however, is hard to control and may have negative effects in terms of mathematical understanding (Buchberger, 2002; Lagrange, 2005). For example, blackboxing may leave students dependent on certain technologies and with little experience of performing the necessary underlying mathematical processes without access to the technology (Nabb, 2010).

\section{TEACHERS' BELIEFS ABOUT MATHEMATICS AS A DISCIPLINE}

When it comes to teachers' beliefs about mathematics as a discipline (or the nature of mathematics), Ernest (1989, p. 250) distinguishes between three philosophical positions among teachers. Firstly, there are the instrumentalists, who see mathematics as an accumulation of facts, rules, and skills to be used to reach some extra-mathematical end. For them, "mathematics is a set of unrelated but utilitarian rules and facts." Secondly, the Platonists view mathematics as a static although unified body of knowledge. Platonists regard mathematics as something discovered, i.e. not invented or created by humans. Thirdly, there are the problem solvers who see mathematics as more of a dynamic and continually expanding field of human creation and invention, i.e. as a cultural product. For them, mathematics is "a process of enquiry and coming to know, not a finished product, for its results remain open to revision" (Ernest, 1989, p. 250). In figure 2, Beswick (2005; 2012) has paired these three positions with teachers' beliefs about mathematics teaching and mathematics learning, respectively. Drawing on a categorization by Kuhs and Ball (1986), Van Zoest, Jones, and Thornton (1994) identify three categories for assessment of pre-service teachers' beliefs about mathematics teaching: contentfocussed with an emphasis on performance; content-focussed with an emphasis on conceptual understanding; and an intermediate between these, referred to as learner-focussed (with an emphasis on social interactions). Beswick has adopted the three categories of teachers' beliefs about mathematics learning from Ernest (1989): skill mastery, passive reception of knowledge; active construction of understanding; and autonomous exploration of own interests. The connections between these three sets of beliefs are illustrated in figure 2, e.g. that someone who holds instrumentalists beliefs about the nature of mathematics is more inclined to believe that mathematics teaching should be content-focussed with an emphasis on performance, and believe that mathematics learning mainly concerns skill mastery through passive reception of knowledge. Both Ernest (1989) and Beswick (2005, 2012) point out that the categorizations are only guiding in the sense that there may exist teachers who fall in more than one category. Still, the categories are useful in assessing teachers' mathematics-related beliefs.

\begin{tabular}{|c|c|c|}
\hline $\begin{array}{c}\text { Beliefs about } \\
\text { the nature of mathematics }\end{array}$ & $\begin{array}{c}\text { Beliefs about } \\
\text { mathematics teaching }\end{array}$ & $\begin{array}{c}\text { Beliefs about } \\
\text { mathematics learning }\end{array}$ \\
\hline Instrumentalist & $\begin{array}{c}\text { Content-focussed with } \\
\text { emphasis on performance }\end{array}$ & $\begin{array}{c}\text { Skill mastery, passive } \\
\text { reception of knowledge }\end{array}$ \\
\hline Platonist & $\begin{array}{c}\text { Content-focussed with } \\
\text { emphasis on understanding }\end{array}$ & $\begin{array}{c}\text { Active construction of } \\
\text { understanding }\end{array}$ \\
\hline Problem solver & Learner-focussed & $\begin{array}{c}\text { Autonomous exploration of } \\
\text { own interests }\end{array}$ \\
\hline
\end{tabular}

Figure 2. Categories of teachers' mathematics-related beliefs (adapted from Beswick, 2005; 2012; based on Ernest, 1989; and Van Zoest et al., 1994). 
But one thing is assessing teachers' beliefs, another thing is first to access them in order to be able to assess them at all. As a means for accessing the teachers' beliefs about mathematics as a discipline, we relied on Jankvist (2015a; 2015b) who defines this category of beliefs through a number of specific questions. We provide these questions in the section on methodology along with the questions used to access the teachers' technology-related beliefs.

\section{METHODOLOGY}

In order to understand how the teachers' beliefs about how technology and mathematics interact and constitute a (maybe not coherent) set of ideas influencing their practice when using technology, we have, as described in the section on setting and background above, chosen to look deeper at three teachers involved in the project. We do this by conducting an in-depth study of these teachers' mathematicsrelated and technology-related beliefs. We have aimed at capturing the individual teachers' beliefs structures.

The data collection was done during a one-day workshop, where the three teachers participated together with two researches (the first and second author of the present article). Prior to the workshop the teachers received a qualitative, openended questionnaire. The questionnaire contained four parts with a total of 55 different questions. For each question, the teachers were prompted to answer both in terms of their practice prior to the intervention (more than 18 months ago), and to the practice after the intervention (covering the last six months). The first part of the questionnaire concerned their teaching practices and asked questions about how often, with what purpose, and in relation to what mathematical topics and work practices they would use technology. The second part of the question concerned the development of 21st-century skills and mathematical literacy (Partnership For 21st Century Skills, 2004; 2011). This part contained questions about how the teachers use technology for developing information and media literacy, communication skills, critical thinking, and systems thinking as well as problem-oriented work, creativity and self-directed behavior, social responsibility and interpersonal competences. The purpose of these first two parts of questions was to get the teachers to talk about their technology use, both prior and after the intervention, in order to some extent to be able to assess the intervention itself. The purpose of the third and fourth part, however, was specifically directed towards the research questions posed in this article. Still, the teachers' answers to questions from part one and two have been useful in drawing up "profiles" of the three teachers and their beliefs, not least as a way of "triangulating" our findings from parts three and four.

The third part of the questionnaire aimed at understanding the teachers' value judgments in relation to the use of technology in mathematics teaching. The questions in this part of the questionnaire evolved around whether or not technologically mediated mathematical talent content was more important than classical paper-and-pencil mathematics. Furthermore, it contained questions about when and how technology should be used in mathematics teaching, to what extent the students should be aware of the connections between their paper-and-pencil activities and technologically mediated mathematical activities. These questions were taken from a variety of literature on the topic (see below). Although we do not present the teachers' answers to all the questions posed, we present the full set of questions here:

- Do you think that paper-and-pencil techniques are rendered redundant by technology? (Schmidt, 1999)

- Do you think that technology is a necessity in the teaching of mathematics today? (Dogan, 2007) 
- To what extent do you agree that pupils must first possess a mathematical concept or procedure before being allowed to use technology in treating the associated mathematical objects or carrying out the procedure? (Fleener, 1995)

- To what extent do you agree that technology makes it possible for pupils to focus more on concept development and concept understanding? (Schmidt, 1999)

- To what extent do you believe that it is important for the pupils to be able to see a connection between e.g. a paper-and-pencil approach and a technology approach? (Drijvers et al., 2010)

- Are there times when technology should not be used in the teaching of mathematics? (Walen et al., 2003)

- Do you think that being able to use mathematics-related technology is part of being able to do mathematics? (Lavicza, 2007)

- To what extent do you believe that technology takes part in shaping pupils' mathematical knowledge (and mathematical competencies) today? (Lavicza, 2007)

The final part of the questionnaire dealt with the teachers' ideas about mathematics as a discipline. It contained questions about the importance of learning mathematics, the role of procedures and proofs in mathematics, the value of the mathematical heritage and axiomatic structure as well as the relations between mathematics, science and society. These questions are taken from Jankvist (2015a; 2015b):

- From time to time you hear that mathematics is used in many different contexts. Not counting basic arithmetic, etc., can you mention any places from your everyday life or elsewhere in society where mathematics is being applied, either directly or indirectly?

- Do you think mathematics has a greater or lesser influence in society today than 100 years ago?

- How do you think that the mathematics in your textbooks came into being? When do you think it came into being? Why do you think it came into being?

- What do you think a researcher in mathematics (at universities and the like) does? What does the research consist in?

- Do you think that parts of mathematics can become obsolete? If yes, in what way?

- Can you give a short description of how an area of mathematics is built?

- Why do we prove mathematical theorems?

- Are the negative numbers discovered or invented? Why?

- Do you believe that mathematics in general is something you discover or invent?

During the workshop the teachers answered the questionnaires on their laptops one part of the questionnaire at the time. Once they completed a part, we had a joint discussion around the content of the questions in that part. In this way we were able to collect data about the individual teachers' beliefs, as well as data showing their discussions and discourses around the questions. All the discussions (interviews) have been transcribed and analyzed with the purpose of answering the research questions in this article. We have treated the individual questionnaires as openended questionnaire data, and we have treated the discussions around each part of the questionnaire as a focus group interview following a semi-structured approach (Kvale 1996). The collected data have been analyzed with a qualitative approach, beginning with reading the full corpus, using beliefs about use of technology in mathematics, mathematics teaching, mathematics learning, and mathematics as a discipline as filters, when constructing our image of the teachers' beliefs structures. We have moved from detailed utterances to broader categories using excerpts from 
the transcript as documentation. In that sense, our strategy for analyzing the data has been theory-driven and guided by an attempt to condensate the meaning of the teachers' utterances.

\section{THE THREE TEACHERS' BELIEFS ABOUT USE OF TECHNOLOGY}

Below we present four interview excerpts related to the third part of the questionnaire given to the three teachers, i.e. the part concerned with their beliefs about the use and role of technology in mathematics teaching and learning.

\section{[1] Paper-And-Pencil Based Math Versus Technology-Based Math}

In the excerpt below, we see the teachers discussing use of technology as a lever potential as well as the relationship between technology-based mathematics and paper-and-pencil based mathematics.

Interviewer: And then the next one, you've all mentioned it before, it concerns using technology as a lever potential, right, that you can get the students to work with the concepts faster...

Teacher 2: Doing that is really interesting, right. It is not so interesting to do frequency tables in statistics, right. The interesting thing is, what does this mean for the specific set of data we're working with, right.

Teacher 1: With GeoGebra you can also see that it is easier for them to construct things. It's faster. Also in relation to some pupils finding it really difficult to draw.

Teacher 2: Yeah. So focus is on the actual math, and not on the surrounding stuff.

Interviewer: How do you see the interplay between technology and paper-andpencil? To what extent do you think that the pupils must be able to see a relationship between these?

Teacher 3: I put down "No, it is not important."

Teacher 1: Me too, I said "Not particularly." To me it is two different approaches. Two different approaches to the same thing, really. I think, paper-and-pencil is something different than if you use the computer.

Teacher 2: "In some cases, it can be important" I've written. Because, there might be some pupils who can't do paper-and-pencil, but understand better when the computer does part of the work... I don't think it has to be connected.

Interviewer: But is it important that the pupils know that what the computer does in principle can be done with paper-and-pencil?

Teacher 3: I think it doesn't matter.

Teacher 2: I don't know. Well. We never question if they enter, say, 15 times 27 into the calculator, that they then need to know "you've could have done this with paper-and-pencil." I guess it is not relevant, because then we keep justifying the paper-and-pencil approach.

Teacher 3: In regard to this [example], with the lower grades at least, it is important to teach them how to do it by paper-and-pencil before using the calculator... to obtain an understanding of what actually happens inside the technology.

The above extract shows that the three teachers tend to be technology supporters with pre-mastery beliefs (cf. figure 1), but also with a certain indifference towards the phenomenon of blackboxing. Apparently it is not relevant for some of them that their students understand how the results generated by the computer are produced or obtained. One exception is perhaps Teacher 3, who expresses post-mastery beliefs through the expression "it is important to teach them how to do it by paper-and-pencil before using the calculator." Still, this statement seems contradictory to her indifferent attitude towards blackboxing. When we the interviewer) asks "is it important that the pupils know that what the computer does 
in principle can be done with paper-and-pencil?" she simply responds "I think it doesn't matter".

\section{[2] Verification Of Mathematical Results Produced By Technology}

In this second excerpt the teachers are discussing whether their students verify and know how to verify the results produced by the computer.

Interviewer: Can the pupils check the results they have obtained by means of a technological tool? Say, previously if you got 7 when solving an equation, you would put 7 into the original equation and check to see if the equality was true. Do they do something similar now as well?

Teacher 1: I doubt it. They would blindly trust the result that came out, i.e. that it was the correct one.

Teacher 2: I don't think they would [check it].

Interviewer: What if they entered the wrong digits, etc.?

Teacher 1: They wouldn't notice. Okay, maybe they would, but from a different viewpoint. It would be like: "No, it can't be that it's $700 \mathrm{~km}$ from..."

Interviewer: But that is different. Would they know how to check? I mean do they know the relationship between the result and what goes into the equation...?

Teacher 2: I think they could. But they would never actually sit down and check. But they would know that the 7 had to go in to $x$ 's place in the equation.

Teacher 3: But this is actually not something you focus on. I mean, if they were to know it and spend time on it, then we would have to focus on it and make them aware of it: "Do the check. Show me that 7 is in fact the right result. How will you prove to me that 7 is the correct answer?" And that is actually doing it the reverse way, right.

Teacher 2: But that's not something we... or I don't spend time on that, at least.

The above supports the observation made from the first excerpt, namely that the three teachers tend to be indifferent towards blackboxing. In this case they declare that neither they nor their students spend much time verifying that the results produced by the computer are actually valid. The teachers put more emphasis on students' ability to judge whether a result obtained by a computer is realistic, and in that sense preventing that wrong typing leads to wrong results.

\section{[3] Undesirable Technology-Based Teaching Situations}

In this third excerpt, the teachers are asked to imagine an undesirable technology-based teaching situation, i.e. a situation that they would like to avoid when teaching mathematics using technology. The type of situation is exemplified by the interviewer in terms of students solving algebraic equations using software. The teachers are asked about their views on such a situation.

Interviewer: Can you imagine any inexpedient or undesirable technology-carried situations i.e. situations you want to avoid? For example, as you mentioned before, if the pupils are to solve ten equations, and then you give them WordMath. That would be a strange task, right.

Teacher 1: No, that would be too easy. They wouldn't learn anything.

Interviewer: Yes, so if they don't learn anything, then that would be inexpedient. Can you think of other such situations?

Teacher 1: It depends on what the goal is. If the goal is to train their skills, then it is no good to give them a calculator. That's the same, right.

Interviewer: Okay, so if there isn't agreement between what the tools can and...

Teacher 1: If the goal is that they learn what happens, when they solve an equation, then it is no good to give them a program, where they solve it without obtaining an understanding of what it is. But when we need them to do something, 
where we don't care how they found the answer, then it's nice for them to know that they can plot it into WordMath...

Teacher 2: Yes, to be able to distinguish between if it is arithmetic/algebraic skills or problem solving skills...

Teacher 3: The arithmetic/algebraic skills are often where you say, okay, we need an understanding of this, so we're going to sit down without technology, right. Still.

Teacher 1: But yes, of course.

Based on the teachers' responses, we may place their beliefs in the left region of figure 1, i.e. the teachers' beliefs may be classified as "old school" and "postmastery". For example, Teacher 1 repeatedly states that if students solve equations using software then "they wouldn't learn anything" or they will solve them "without obtaining an understanding of what it is". A similar situation occurs with Teacher 3 , when she states that if what is needed is an understanding of arithmetic and algebraic skills, then "we're going to sit down without technology" - and Teacher 1 agrees.

\section{[4] Technology As Shaping Mathematical Knowledge And Competencies}

In the fourth excerpt, the question raised is aimed at bringing about the teachers' views on the role that technology can have in shaping students' knowledge and mathematical competencies. To what extent do the teachers find that technology has an impact on the way their students understand and do mathematics?

Interviewer: To what extent do you think that technology today plays a part in shaping pupils' mathematical knowledge and mathematical competencies?

Teacher 1: I've written: “I don't think technology plays a part in shaping pupils' mathematical knowledge, but it is a tool and a new way of coming from A to B."

Teacher 2: Yeah, but they do more. They may reach a higher level of understanding, because...

Teacher 1: Yes, but it's still... they may learn more, but it's still about getting from A to B. There are many ways of getting from $A$ to $B$.

Teacher 2: Yeah, or getting from $A$ to $C$ instead, right.

Teacher 1: Yes, yes.

Teacher 3: I see it differently. I think, their everyday is this technological world. So, they will be able to connect it faster to school subjects. [...] I've experienced that if you relate to or use something from the world they know with technology, it is easier for them. With Minecraft, for example, it was like "Oh, is it just that. Well, then let's build the house. There is so much space inside. So, the volume is..." They knew it alright.

Teacher 2: With Minecraft it actually does shape their knowledge. Because it is connected to [something], instead of just being some theoretical mathematics. Then it is actually usable in the world, right.

Teacher 1 seems to consider the technological tools as an element not affecting the configuration of the students' mathematical understanding. It seems that for her, technology serves mainly as a lever potential providing new ways to obtain results. Teachers 2 and 3, however, seem to have a different perspective. Teacher 2, for example, states that the Minecraft software "actually does shape their knowledge" and she also considers that through the use of these tools students "may reach a higher level of understanding". This last statement suggests that Teacher 2 has exploratory beliefs about the use of technology. In turn, Teacher 3 argues that the Minecraft software may help students to understand mathematical concepts, exemplified by the concept of volume of a geometric structure. Thus, here, Teacher 3 also appears to have exploratory beliefs about the use of technology. 


\section{THE THREE TEACHERS' BELIEFS ABOUT MATHEMATICS}

We now present four interview excerpts related to the fourth part of the questionnaire given to the three teachers, i.e. the part concerned with their beliefs about mathematics as a discipline.

\section{[5] Mathematical Understanding As A Strategy For Differentiated Teaching}

In the fifth interview excerpt the teachers discuss mathematical understanding and the need for students to know why a certain mathematical procedure works and gives correct results. We show that the teachers in general hold beliefs about the nature of mathematics that makes it less important to understand all aspects of a procedure than to be able to perform it.

Interviewer: To what extent do you agree that it is important to understand why a mathematical procedure works? [...]

Teacher 2: In some instances, it is okay just to be able to do a procedure, get a result, and then work on with this. So, sometimes it's okay to skip that part, even though it is not optimal.

Interviewer: But now you are talking about a strategy of differentiated teaching?

Teacher 2: Yes.

Teacher 1: I've written "Not at all" actually. Because I think that in math teaching today we are more process oriented. That is, they work with intermediate results and stuff. Maybe these are different things, the intermediate results and the process in it, but I still think....

Interviewer: Okay, but is it important to know how the procedure works, or why it works?

Teacher 1: It is important to be able to carry it out.

Teacher 3: I've also said that it is a tool for differentiated teaching. There are some pupils who don't have the abilities to figure out how it works, in particular at the higher levels, and then you can't demand them to be able [to understand]. If they don't have the abilities. At higher levels they may need to know. But not at primary level. So, I pass on the responsibility.

Interviewer: Take algorithms, for example, something similar to a "recipe". Now, it is one thing to be able to follow the "recipe" [algorithm], but it is something else to be able to understand why it gives you the correct result, right?

Teacher 3: You can require this from some students. And not from others. It depends on the difficulty of the task.

Teacher 2: Agree.

In the above excerpt, we pose the question of the need to understand why a mathematical procedure works, and the teachers answer through a discussion of what may be required from students in terms of ability to understand. The discussion begins with an attempt to clarify how much the students need to be able to understand in order to apply a procedure. The teachers seem to agree that the depth of understanding is a valuable parameter in supporting teaching differentiation in terms of targeting individual students at different levels. In this sense, the teachers make the question of mathematical truth (how do we know that an algorithm works) into a question of teaching (who needs the deeper knowledge).

Furthermore, the teachers all agree that the ability to carry out certain mathematical procedures is more important than being able to understand what is going on, at least for the majority of their students. Hence, this can be taken as evidence that all three teachers consider mathematics not as a logical structure, but rather as a tool and a way of addressing problems. Following Ernest (1989), this 
suggests that they do not possess a Platonist-oriented beliefs system (cf. figure 2). Rather, they seem to enact instrumental beliefs about mathematics. In terms of beliefs about mathematics teaching, in this excerpt the teachers seem more focused on student performance than on student understanding, because they all consider the understanding of a procedure to be something to be addressed mainly by the better students, and also as less important than being able to execute the procedure. This points in the direction of performance-oriented beliefs about mathematics teaching (Van Zoest et al., 1994).

\section{[6] On Proofs And Mathematical Structure}

We also discussed the notion of proof and the necessity of proving mathematical results. Proofs are not typical for the teachers to deal with in their teaching. But despite, proving being a somewhat unusual activity for the teachers, the question still allows us to see certain trends in the teachers' beliefs about the discipline of mathematics.

Interviewer: Next question: How often do you prove mathematical results as part of you teaching?

Teacher 2: I think proof is... well, it is a big word, right.

Interviewer: Well, argue for mathematical results then.

Teacher 2: Well, if you can see a connection and an understanding of the result is right... is that to prove it, or is that not to prove it? I mean, how high a theoretical level is needed in order to call something a proof? I think more like, it is the connection and understanding of, well, it is right what I'm doing here.

Teacher 3: Yeah. Explanation.

Teacher 1: Explaining the pupils, by means of different methods.

Teacher 2: I don't know if that qualifies as proving.

Teacher 3: No, precisely, mathematical proving is... a little high flying, right.

Interviewer: [...] As an example take the proof that there are 180 degrees in a triangle. Do you work with something like this at all? You do work with this theorem, at least.

Teacher 2: Yes. But not so much. There is not so much proof involved...

Teacher 1: On the whole, we don't really work with proofs...

Teacher 2: The Pythagorean theorem, the area of the circle and things like that. But that's not much, right. [...] Maybe in total five proofs. But that's max, I think.

Teacher 3: My perspective on proofs has been explaining mathematical results. For example, volume, I've said: "this side and this side and this side multiplied". So, this is a proof, I've been thinking. And then the formula, that's it. But mathematical proofs, I don't think it's... it's not a big part of the curriculum. No.

As evident, the teachers are not very used to working with proofs. But they do say a few things that tell us about their conception of mathematics. First of all, they consider proofs as mainly a question of explanations and not really related to concerns about the truth of mathematical statements. This seems as a peculiarity in a first approximation, but previously we also saw that the teachers had what Ernest would describe as an instrumental or even problem solving belief about the nature of mathematics, and therefore possibly very little focus on the inner structures of the discipline. Hence, for the teachers, the role of proof can hardly be related to the establishment of mathematical truth, since the problem solving image of the mathematics is not really concerned with mathematical truth as anything but efficiency of mathematical approaches in practical problem situations.

To some extent, the teachers' ideas about proving are sound and meaningful in the way that they consider proving as a way of explaining mathematical ideas. However, the idea that proofs are establishing truth is not really adopted. Hence, when Teacher 3 describes that her perspective on proof is "explaining mathematical 
results" she is not enacting an instrumental belief of what mathematics is, and not a Platonist conception either.

\section{[7] What Mathematicians Do}

The teachers did have different ideas about what mathematical research is and how it is enacted. Of course, mathematical research was not a familiar practice to the teachers. Still, thinking and talking about the practice of mathematical research do allow them to articulate some of the perceptions they - perhaps implicitly - held about this.

Interviewer: What do mathematicians, e.g. at universities etc., do? In what does their job consist?

Teacher 3: I've written: "They collect some data and reason about it in order to develop the discipline." I don't know.

Teacher 1: I've written: "Solve mathematical problems. Find formulas, solutions. See if they can crack the code about $\pi . . . "$

Teacher 2: I've just put a question mark.

Interviewer: Can they make "new mathematics"?

Teacher 2: They look at new connections in some areas. I know that it's engineers who do the programming. But still, some of the math they know, well, some of it must be researched at the universities.

Interviewer: New connections, of course, but can you talk about "new mathematics"? Could they come up with new mathematics? Not that it might necessarily make the other math untrue, but...

Teacher 3: I guess. I suppose not everything is already discovered. Didn't they just discover something, what was it, something with quantum... no, I can't remember. Well, it was something with not only 0 and 1 being able to make up the binary number system. But that they discovered a new number system. Quantum, what was it called? Something with quantum...

Teacher 2: I don't know. I have no idea whatsoever.

Again we see both instrumentalist and problem solving perspectives on the discipline of mathematics, beginning with Teacher 3 saying that mathematicians "collect data" and Teacher 1 that they "solve mathematical problems", "find solutions" or "crack the code". Although Teacher 2 seems a bit more cautious in pointing out what mathematicians do, her way of trying to discuss it is still one of considering what engineers do. Upon trying to make the question a bit more concrete with a reference to new kinds of mathematics, Teacher 3 agrees that maybe not everything is already "discovered". The use of the term "discovered" is quite deliberately used by Teacher 3 , since in a previous discussion she favored "discovery" over "invention" (cf. later). Teacher 3 ends up suggesting that maybe mathematicians recently have "discovered a new number system."

\section{[8] If Math Can Become Obsolete}

In the eighth and final excerpt, the teachers are asked if mathematics, or parts of mathematics, can become obsolete.

Interviewer: Are there parts of mathematics that can become obsolete? What, for example?

Teacher 1: So, I think, well, I know that... multiplication tables will still be there, but we get some new technology to replace them. So, the math around them is obsolete. I mean, the use of it.

Teacher 2: Well, but then it is not the actual math that is obsolete, is it?

Teacher 1: No, but we have some new math, which replace...

Interviewer: We have new technology? 
Teacher 1: We have a new technology that we can use instead.

Teacher 2: I've written "Basically, no. But that it [the math] may be developed, and the tools and aids may be replaced." But $2+2$ is still 4 , even if you use your fingers, if you use a computer, or something else.

In this excerpt, Teacher 1 is talking about how students can perform with mathematical technology, and she does not really differentiate between the mathematics and the mathematical technologies. In that sense, mathematics can according to Teacher 1 - become obsolete. The continuity between mathematical concepts and mathematical technologies that this understanding reveals is in direct contrast to what Ernest describes as a Platonist conception of mathematics. But in a radical pragmatic conception as the one enacted by Teacher 1 , this continuity makes sense. Each problem situation comes with its own mathematical structures and hence new mathematical technologies mean a "new" kind of mathematics. Teacher 2 does not agree; " $2+2$ is still 4 " as, she says.

\section{THE INDIVIDUAL TEACHERS' MANIFESTED BELIEFS}

We now present an analysis of each of the three teachers. First we describe their background, also in relation to their use of technology, and then we propose an individualized analysis of the beliefs that they manifest about the use of technology in the teaching and learning of mathematics and about mathematics as a discipline. These analyses are firstly based on the eight previously presented interview excerpt, and secondly backed by teachers' comments elsewhere in the interview (or questionnaire). However, the questionnaire data mainly enters the analyses when the teachers refer to their questionnaire answers - or occasionally if we experienced a shift of discourse by a teacher during the discussion, then we would cross-check with their questionnaire answers before categorizing their beliefs.

Teacher 1: An "old school" instrumentalist

Teacher 1 has been a teacher for eleven years. She recalls having heard a little related to ICT as part of her teacher education. But mainly she has been acquainted with ICT during a module in a further educational program with the aim of becoming a counselor for mathematics teacher colleagues. Here she learned to use both Excel and GeoGebra.

The answers provided by this teacher make us presume that her beliefs about the use of technology for teaching mathematics mainly tend to be somewhere in between "old school" and post-mastery. On at least two occasions during the interview, Teacher 1 states that technology should not be used to develop skill mastery, nor when the purpose is that students gain an understanding of the mathematical processes that they apply, particularly when solving an equation. It seems that the teacher perceives technology as a lever potential, i.e. a tool that helps students to perform mathematical procedures faster and more easily, but that this is not appropriate to promote mathematical understanding among the students.

In relation to her beliefs about mathematics as a discipline, Teacher 1 to a large extent enacts an instrumentalist point of view. She expresses a content-focused orientation towards mathematics teaching with an emphasis on students' performance, in particular in relation to possessing skills to be able to carry out mathematical procedures. The notion of proof does not directly seem to apply to her and her teaching, which can be explained by the instrumentalist beliefs and the little focus on inner structures in mathematics. To some extent the instrumentalist view can also explain why she does not differentiate between actual mathematics and mathematical technology - recall that for Teacher 1 mathematics could become obsolete, because associated technologies would become outdated. As mentioned, for Teacher 1 , one gets the impression that each mathematical situation comes with its own mathematical structures, and doing mathematics is about being able to 
uncover the structures of the specific situation in order to reach the extramathematical end.

In the interview data, we find further support for the above classifications of Teacher 1's beliefs system. For example, Teacher 1 is the first to state that the computer is just "replacement for the paper notebook." In regard to the use of technology as a lever potential, Teacher 1 mentions that in particular when the pupils are doing something related to statistics, the technological tools are useful. Still, she also says "there are some things, where - in terms of teaching - we still hang onto the paper-and-pencil techniques, and that the pupils master these first" after which she mentions algebra as an example.

Teacher 2: A technology supporting problem solver

Teacher 2 has been a teacher for twelve years. As part of her teacher education, she was only acquainted briefly with Excel. Other software she now knows, she has become familiar with during in-service teacher courses at her school.

We classify Teacher 2's beliefs as "technology supporter" with a tendency toward exploratory beliefs. We claim this because the teacher ensures that the computer can help some students - those who may have problems working with paper-andpencil techniques - to obtain a better mathematical understanding, when the computer does part of the algorithmic work. When she is asked, if she believes that technology shapes the mathematical knowledge and competencies of the students, she affirms that it does and that it can also help them to achieve higher levels of understanding.

As for Teacher 2's beliefs about mathematics as a discipline, she to some degree fits the description of Ernest's "problem solver". Teacher 2's perspective on mathematics teaching is more learner-focussed, than Teacher 1's for instance. For example, when asked about the need to know why a procedure works, she states that occasionally it may be okay to just use a procedure to obtain a result, "even though it is not optimal". Also, when asked about what mathematicians do, Teacher 2 tends towards a more application oriented or problem solving perspective by referring to engineers and mathematics behind programming. To what extent Teacher 2 views mathematics as a dynamic and continually expanding discipline, as Ernest's problem solver does, is difficult to say, since she may never have given this aspect of the discipline of mathematics much thought. However, she does see mathematics as a rather experimental undertaking and process of enquiry, which fits with Ernest's description. Still, when Teacher 1 suggests that some mathematics can become obsolete due to outdated technologies, Teacher 2 does not take the bait, but claims that " $2+2$ is still 4" no matter the technology used to find this out. So, although perhaps mainly a "problem solver", Teacher 2 may also possess elements of Ernest's Platonist perspective on mathematics.

In the interview data we also find support of the above classifications of Teacher 2 's beliefs system. In relation to the "problem solver's" beliefs about mathematics learning as "autonomous exploration of own interests" (cf. figure 2), Teacher 2 talks about technology as "good for testing out things", e.g. that the sum of the angles in a triangle equals 180 degrees, etc., and furthermore she talks about technology as enabling and motivating the students to "experiment" much more. This is connected to the way she sees technology as a lever potential, e.g. "there is more focus on the actual mathematics than on all the surrounding stuff.". From a learner's perspective, Teacher 2 finds it important that her pupils develop a "critical sense of assessment" and "do not just swallow whole what the computer spits out." As a potential explanation of Teacher 2's beliefs that mathematics as a discipline is rather "experimental" in nature and good for testing out hypotheses (cf. above), we draw the attention to her belief that mathematics is a natural science, because "it takes its departure point in something else... mathematics is naturally embedded in nature".

Teacher 3: A mishmash of contradictory beliefs 
Teacher 3 has been a teacher for nineteen years. The only ICT-related aspect she recalls from her teacher education is a six months module, where they worked with fractals on computers: "I never understood it, and I always thought it was highly irrelevant. ... Our teacher, he was very fascinated by it. I've never used it since."

The case of the third teacher provides us with an example of how some of the beliefs that teachers manifest, both about the role of technology in the teaching and learning of mathematics as well as the beliefs about mathematics as a discipline, can be quite contradictory.

During the interview Teacher 3 makes statements that could be clearly classified as post-mastery. For example, when she says that in lower grades, "it is important to teach them how to do it by paper-and-pencil before using the calculator." However, when asked if she believes that technology plays a part in shaping pupils' mathematical knowledge and competencies, she mentions the use of the game Minecraft as an example of how technology can make the understanding of mathematical concepts easier and more meaningful for kids, e.g. in the case of the concept of volume. Hence, on the one hand, her beliefs can be classified as postmastery or "old school", but on the other hand it seems that these beliefs coexist with other beliefs of a more pre-mastery nature.

Teacher 3's beliefs about mathematics as a discipline also appear rather contradictory. Firstly, she articulates beliefs along the line of an instrumentalist or a problem solver, when she states that mathematicians "collect some data and reason about it". Secondly, she is headstrong on mathematics being discovered, both when talking about not everything already being discovered (cf. excerpt 7 above) and in previous discussions with the other two teachers, where she - rooted in her other subject physics - argues strongly against mathematical notions, concepts, etc. as being invented in any way. But although this would support Ernest's Platonist beliefs system, she does not put too much value into the role of proofs and proving as providing mathematical truth. In fact, she finds proving a little "high flying" and as seen above from the example she gives, her conception of what constitutes a mathematical proof is not too clear-cut either. As for her beliefs about mathematics learning, these appear to be more along the lines of skill mastery and passive reception of knowledge, i.e. an instrumentalist (cf. figure 2). But at the same time, in relation to technology use, it is Teacher 3 who states that when it comes to arithmetical and algebraic skills and if an actual understanding is needed, then "we're going to sit down without technology" which actually supports a Platonist beliefs system (cf. figure 2). Still, Teacher 3 is the first to say "yes" to the question of whether paper-and-pencil techniques will be made redundant due to the introduction of technology. In fact, she believes that it is merely a matter of knowing and having at one's disposal the "right technologies" - and once having these, then everything is possible.

And we find further surprising contradictions when digging into the interview data. For example, Teacher 3 does not find that it is important for the students to see the connections between technological approaches and paper-and-pencil approaches, and when asked if the students need to know that what the computer does in principle can be done by hand as well, she replies "I think it doesn't matter". Shortly after, however, she states that "math concerns proportions and relationships - so to get a feeling of this, before being able to plot it into some program, you must have some kind of basic understanding of what it is", hence insinuating that such "basic understanding" cannot be reached by means of technology. Again, we notice that in one instance Teacher 3 argues in line with exploratory beliefs and in the next instance she appears to have post-mastery beliefs. In relation to mathematics as a discipline, although providing several Platonist viewpoints throughout the interview, she apparently does not really see mathematics as a discipline. Because when asked which other disciplines (subjects) mathematics resembles most, she 
says "we don't see mathematics as a discipline in that sense... well, yes, it is a discipline, but it is also very much a tool to understand other disciplines." Finally, in relation to mathematical competencies, Teacher 3 is also the one to provide the somewhat odd statement that "being able to do mathematics is being able to transform something abstract into something real.". On the one hand, this acknowledges mathematics as an abstract structure, but on the other hand it appears to be the viewpoint of Ernest's "problem solver". Apparently, for her "doing" mathematics is the same as being able to "apply" mathematics. At any rate, one would think that doing mathematics also is very much being able to come up with the abstract and general structure which encompasses potential concrete applications. But of course, if one believes that all mathematics is "discovered" we don't really have to "come up" with anything.

\section{CONCLUDING DISCUSSION}

In this section we first provide answers to the three research questions of the study presented in this article. Next, we discuss the validity of the research findings as well as the research methodology applied in the study. Finally, we discuss potential consequences of the research findings for mathematics education.

\section{ANSWERING THE RESEARCH QUESTIONS}

In the above we have shown how the three teachers enact different beliefs systems. We know from beliefs research that teachers' beliefs have influence on their practice (e.g. Drijvers et al., 2010), but we also know that there is no direct simple imperative between beliefs and teaching practice. However, what we learn from the analysis above is that teachers' beliefs about mathematics and about technology do intersect and influence one another.

In our data we made the observations that Teacher 1 may be placed in the lefthand side of figure 1 and at the top of figure 2, i.e. that her beliefs on technology use resemble those of "old school" and post-mastery, while her beliefs about the discipline of mathematics can be characterized as instrumentalist. According to Beswick (2012) this implies that Teacher 1's beliefs about mathematics teaching and learning are skills and performance oriented, which we also found evidence for in the data. Similarly, Teacher 2 may be placed in the right-hand side of figure 1 and at the bottom of figure 2, i.e. that she is a technology supporter holding exploratory beliefs, while she can be characterized as a "problem solver" when it comes to her beliefs about mathematics as a discipline, implying a focus on the learner's perspective in terms of mathematics teaching and learning (cf. figure 2). Also this was backed by the data. In figure 3, we have attempted to "map" the teachers' technology-related beliefs and their mathematics-related beliefs against one another. As seen for Teacher 1 and Teacher 2 they cannot be placed in only one cell of the matrix, but occupy two and three cells, respectively.

For Teachers 1 and 2 we were also able to partly explain some of the connections in their beliefs systems regarding technology use and the discipline of mathematics, i.e. to make potential inferences between the two sets of beliefs. Teacher 2, for example, saw mathematics as a natural science, which to some degree explained her beliefs about the discipline of mathematics as being a rather experimental undertaking, which again provided an explanation for her exploratory beliefs regarding the use of technology in the teaching and learning of mathematics; e.g. mathematics is about "testing hypotheses" and technology is a useful tool to do exactly so. Teacher 1 had very little focus on the inner structures of mathematics, e.g. proofs. This instrumentalist view was used to also explain why she did not differentiate between mathematics and technology, i.e. the instrumentalist sees 
mathematics not only as an accumulation of facts and rules but also of skills to reach some end, no matter whether these skills be technologically-oriented or not. That there is no real difference between these skills for Teacher 1 is partly explained by her view of the computer as merely a replacement for the paper notebook. Hence, it is also understandable that Teacher 1 does not think that technology plays a part in shaping the students' mathematical knowledge and competencies.

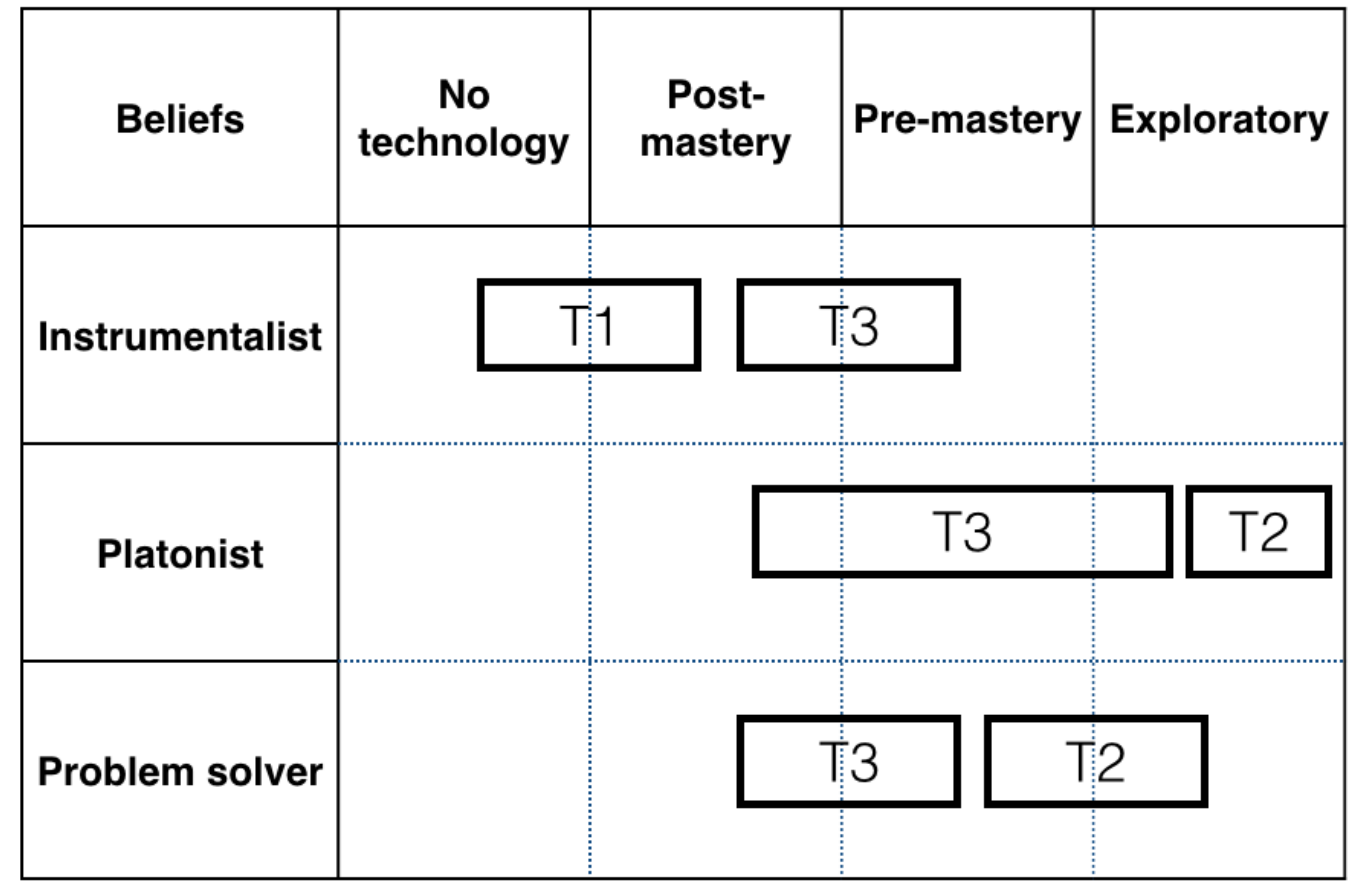

Figure 3. An attempt to "map" the teachers' beliefs systems. Teacher 1 is T1, Teacher 2 is T2, and Teacher 3 is T3.

Due to the number of seemingly inconsistent beliefs, Teacher 3 most certainly also occupies several cells in figure 3. As seen, when it comes to her beliefs about mathematics as a discipline, she possesses aspects of all three of Ernest's (1989) beliefs systems, i.e. instrumentalist, Platonist and problem solver. However, in terms of technology use, her beliefs system is centered around post-mastery and premastery, with a few digressions to exploratory beliefs. Unlike the cases of Teacher 1 and Teacher 2, the case of Teacher 3 , as seen through the data, does not really provide much explanation for her far-reaching beliefs about mathematics as a discipline, her beliefs about use of technology in the classroom, and their interrelations. This also means that it is practically impossible to make any clear inferences for Teacher 3's beliefs system as could to some extent be done for Teachers 1 and 2. Still, it makes sense that when possessing elements of all of Ernest's three categories, then she should also possess a wider range of beliefs about the use of technology, which she does. Following Leatham's (2006) line of reasoning in the sense that beliefs can be organized as sensible systems, we could say that the different beliefs that Teacher 3 manifests, although they may seem contradictory, could be internally organized so as to make full sense to her and without being discordant. It could be the case that her pre-mastery and post-mastery beliefs about the use of technology are housed in different belief clusters, and trigger depending on the area or mathematical topic being treated, e.g.: pre-mastery beliefs when it comes to promoting arithmetic and algebraic skills, especially in the lower grades ("it is important to teach them how to do it by paper-and-pencil before using the calculator"), and post-mastery beliefs in the case of mathematical topics that may be connected to students' technological daily life, such as the exploration of the concept of volume through the video game Minecraft ("I've experienced that if you relate to 
or use something from the world they know with technology, it is easier for them"). This explanation of the seemingly contradictory beliefs of Teacher 3 corresponds with other interpretations of belief structures (for example Rokeach, 1960; Green, 1971; Cooney, Shealy \& Arvold, 1998) in the sense that it is quite possible to possess contradictory beliefs, but coexisting since they are stored in clusters isolated from one another. Cooney et al. (1998) suggest that the inculcation of doubt and the posing of perplexing situations can serve as a basis to promote positive changes in the mathematics teachers' belief structures. We find that such situations could be aimed at making teachers' contradictory beliefs explicit, so that they reflect on them and become aware of their existence.

Although one may find that the beliefs system of Teacher 1 - and even Teacher 2 is not always necessarily the most convenient for all practical situations of teaching and learning of mathematics, the systems still appear somewhat consistent. Hence, these teachers must be expected to transmit to their students more or less consistent beliefs - or images - of mathematics and more or less consistent beliefs or policies - on the use of technology in the classroom. As shown by Jankvist, Misfeldt and Iversen (preprint), students are very sensitive to changes in teachers' policies about technology use in the classroom. Hence, if consistent beliefs about mathematics as a discipline prompt consistent beliefs and policies about technology use, as we hypothesize they do, then inconsistent beliefs about the discipline of mathematics may be expected to lead to somewhat inconsistent beliefs about and policies on technology use in the classroom. Drawing on Jankvist et al. (preprint) this is far from productive in terms of sustaining a reflected use of technology in the mathematics classroom, e.g. one that not only serves pragmatic purposes but also epistemic purposes (Artigue, 2002).

\section{VALIDITY OF THE RESULTS AND FINDINGS}

We are of course aware of the criticisms that the construct of belief and the research on beliefs itself have had throughout the years in the field of mathematics education. For instance, the lack of a unified view on the meaning of the concept; and the fact that beliefs are not directly observable entities, but inferred from answers to questionnaires, interviews and perhaps classroom observations - all this questioning the accuracy of such inferences (Leder, 2015). Even though our results do not escape such criticism, we find that their validity still can be sustained.

Although our results are not supported by a triangulation between different data sources, they are obtained upon triangulation between different moments in and instances of the interview. That is, our results are based on answers provided by the teachers on similar issues (past and present use of technology; beliefs on the use of technology in mathematics education; students' 21st century competencies; and beliefs on mathematics as a scientific discipline), but enacted by different questions in the respective parts of the interview. This process has allowed us to build more consistent and reliable profiles of the beliefs systems that underlie the teachers' answers. Furthermore, our results have a certain explanatory power (Schoenfeld, 2007), in the sense that they provide a plausible explanation of the relations between the beliefs that teachers hold about the use of technology in mathematics education (more "traditionalist" beliefs in the case of Teacher 1, and more "progressive" in the case of Teacher 2), and their beliefs about mathematics as a (scientific) discipline. We have also presented the case of Teacher 3, who appears to possess more messy sets of beliefs and who as a case therefore is more difficult to explain.

The large difference in the teachers' beliefs about mathematics and use of technology is an essential finding in the study. From just studying these three teachers we see great diversity. The reason for the great diversity is of course partly 
individual differences among the teachers interviewed. However, as pointed to by Skott (2015), we should not only look for explanations to the origin and patterns of beliefs identified in the individual personalities of the teachers, but also - ideally take into consideration the situations that the teachers engage in, and the patterns of participation that they enact in such situations. This, however, is beyond the scope of the present study.

\section{POTENTIAL CONSEQUENCES OF THE RESEARCH FINDINGS}

The potential consequences of the findings of this research study are mainly of a practical nature, although they may also have implications for research in the field of mathematics education. Both types of repercussions are examined below.

On a tangible level the previous analysis provides us with insight about the diversity of teachers' beliefs about mathematics and technology use, as well as the presented model - based on Beswick (2005; 2012), Ernest (1989) and Van Zoest et al. (1994) - that can be instrumental in teacher education and in-service training of teachers. Acknowledging and understanding this diversity in beliefs across different teachers is the first step towards an open and professional discussion of approaches to the use of technology in mathematics teaching, and apart from suggesting the importance of such a discussion our analysis may also serve as an artifact supporting such a discussion. The educational importance of facilitating this discussion seems obvious, since there is research evidence indicating that the beliefs teachers hold about mathematics come to shape their students' beliefs about the subject (e.g. Carter \& Norwood, 1997). This suggests that the beliefs that teachers hold on the use of technological tools, and the way they organize the use of these tools in the classroom also influence students' beliefs about the role of these tools, and how they should be used in the classroom. For instance, there are research results showing that a student may feel guilty for using a calculator during a problem-solving process, if the student repeatedly hears from the teacher that calculators should only be used as a last resort when solving a mathematical problem (McCulloch, 2011). This potential influence of teachers' beliefs about the use of technology is a variable that should be considered, if our purpose is to promote a more coherent and multifaceted integration and adoption of technological tools in the mathematical practice of students, since some teachers' beliefs structures may have a tendency to foster less productive uses of technology. For instance, beliefs of the "old school" or post-mastery type, as those exhibited by Teacher 1, could determine that technology is used only as a tool to verify results or not used at all - leaving aside the exploratory and experimental potential that these tools can provide to the students during the construction and reification of mathematical concepts.

Of course, the teachers' beliefs about mathematics as a scientific discipline can also have an effect on their students' beliefs about this. The nature of this effect can provide explanations not only about the mechanisms that influence how students use technology, but also about some of the issues related to the transition between different educational levels. Take for example the well known and well-documented problem of transition from secondary to tertiary education (e.g. De Guzman, Hodgson, Robert \& Villani, 1998), which refers to the difficulties experienced by college freshmen to suit the mathematical practices and content addressed at the university level. Several explanations of didactical, epistemological, cognitive and sociological nature have been provided throughout the years to this problem. However, we hypothesize that the influence that mathematics teachers' beliefs may have on students' beliefs about the nature of mathematics as a scientific discipline, may equally well provide partial explanation for the phenomenon. As illustrated by our findings, all the teachers who participated in this study were not used to 
working with proofs, nor did they seem to perceive proofs as a fundamental component of the internal structure of mathematics. Surely such beliefs are reflected in their teaching practice - as evidenced by the teachers' utterances in the interview - which in turn not only limit the opportunities that students have to work with proofs, but also potentially constitute a limited understanding by the students of the role of proofs in mathematics. And not only related to proving and proofs, but also to the very conception of mathematics itself and the associated mathematical activities. Take for example the statement by Teacher 3 that "being able to do mathematics is being able to transform something abstract into something real." Surely Teacher 3's students must be surprised when later on in their mathematical education being asked to actually work with the abstract structures. Thus, when students enter into upper secondary or tertiary level, where the internal structures of the discipline of mathematics have a much more prominent role, it makes perfect sense to expect them to experience a cultural clash between their existing beliefs about mathematics, as imposed on them by their primary and secondary teachers, and the beliefs which their upper secondary or tertiary teachers hold about the discipline of mathematics and what it means to be "able to do mathematics".

Due to the explanatory power, we believe that the mathematics education research community could benefit from promoting and developing more empirical and theoretical studies on the beliefs that teachers and students have about mathematics as a (scientific) discipline. Although there are a some recent studies concerned with this kind of beliefs (e.g. Blömeke \& Kaiser, 2015; Jankvist, 2015), further studies could be wished for. Such studies ought then to try to identify the beliefs and representations of mathematics as a scientific discipline in the different actors of the educational system (teachers, students, parents, textbooks, etc.), and the connections and interactions of these beliefs and representations with other phenomena related to the teaching and learning of mathematics. The research study reported in this article is a step in that direction.

\section{REFERENCES}

Artigue, M. (2002). Learning mathematics in a CAS environment: the genesis of a reflection about instrumentation and the dialectics between technical and conceptual work. International Journal of Computers for Mathematical Learning, 7(3), 245-274. doi: 10.1023/A:1022103903080

Beswick, K. (2005). The beliefs/practice connection in broadly defined contexts. Mathematics Education Research Journal, 17(2), 39-68. doi: 10.1007/BF03217415

Beswick, K. (2012). Teachers' beliefs about school mathematics and mathematicians' mathematics and their relationship to practice. Educational Studies in Mathematics, 79(1), 127-147. doi: 10.1007/s10649-011-9333-2

Blömeke, S. \& Kaiser, G. (2015). Effects of motivation on the belief systems of future mathematics teachers from a comparative perspective. In B. Pepin \& B. RoeskenWinter (Eds.), From Beliefs to Dynamic Affect Systems in Mathematics Education. Exploring a Mosaic of Relationships and Interactions (pp. 227-243). Switzerland: Springer. doi: 10.1007/978-3-319-06808-4_11

Buchberger, B. (2002). Computer algebra: the end of mathematics? ACM SIGSAM Bulletin, 36(1), 3-9.

Carter, G. \& Norwood, K.S. (1997). The relationship between teacher and student beliefs about mathematics. School Science and Mathematics, 97(2), 62-67. doi: 10.1111/j.19498594.1997.tb17344.x

Cooney, T.J., Shealy, B.E. \& Arvold, B. (1998). Conceptualizing belief structures of preservice secondary mathematics teachers. Journal for Research in Mathematics Education, 29(3), 306-333.

De Guzman, M., Hodgson, B.R., Robert, A. \& Villani, V. (1998). Difficulties in the passage from secondary to tertiary education. In Proceedings of the International Congress of Mathematicians (pp. 747-762). Berlin: Documenta mathematica. 
Dogan, M. (2007). Mathematics trainee teachers' attitudes to computers. In M. Joubert (Ed.), Proceedings of the British Society for Research into Learning Mathematics 28(2), (pp. 1924). United Kingdom: BSRLM.

Dreyfus, T. (1994) The role of cognitive tools in mathematics education. In R. Biehler, R.W. Scholz, R. Sträßer \& B. Winkelmann (Eds.), Didactics of Mathematics as a Scientific Discipline (pp. 201-211). Dordrecht: Kluwer. doi: 10.1007/0-306-47204-X

Drijvers, P., Doorman, M., Boon, P., Reed, H. \& Gravemeijer, K. (2010). The teacher and the tool: instrumental orchestrations in the technology-rich mathematics classroom. Educational Studies in Mathematics, 75(2), 213-234. doi: 10.1007/s10649-010-9254-5

Erens, R. \& Eichler, A. (2015). The use of technology in calculus classrooms - beliefs of high school teachers. In C. Bernack-Schüler, R. Erens, T. Leuders \& A. Eichler (Eds.), Views and Beliefs in Mathematics Education. Results of the 19th MAVI Conference (pp. 133144). Germany: Springer. doi: 10.1007/978-3-658-09614-4_11

Ernest, P. (1989). The impact of beliefs on the teaching of mathematics. In P. Ernest (Ed.), Mathematics Teaching: The State of the Art (pp. 249-254). New York: Falmer.

Fleener, M.J. (1995). The relationship between experience and philosophical orientation: a comparison of preservice and practicing teachers' beliefs about calculators. Journal of Computers in Mathematics and Science Teaching, 14(3), 359-376.

Forgasz, H.J. (2002). Teachers and computers for secondary mathematics. Education and Information Technologies, 7(2), 111-125. doi: 10.1023/A:1020301626170

Furinghetti, F. \& Pehkonen, E. (2002). Rethinking characterizations of beliefs. In G.C. Leder, E. Pehkonen and G. Törner (Eds.), Beliefs: A hidden variable in mathematics education? (pp. 39-57). Dordrecht: Kluwer. doi: 10.1007/0-306-47958-3_3

Fullan, M.G. (1991). The New Meaning of Educational Change. New York: Teachers College Press

Gill, M.G., Ashton, P.T. \& Algina, J. (2004). Changing preservice teachers' epistemological beliefs about teaching and learning in mathematics: An intervention study. Contemporary Educational Psychology, 29(2), 164-185. doi: 10.1016/j.cedpsych.2004.01.003

Georgsen, M., Fougt, S.S., Mikkelsen, S.L.S. \& Lorentzen, R.F. (2014). Interventionsdesign $i$ demonstrationsskoleprojektet IT-fagdidaktik og lærerkompetencer $i$ et organisatorisk perspektiv. Retrieved from: http://auuc.demonstrationsskoler.dk/ sites/default/ files/IT-fagdidaktik/interventionsdesign_i_demonstrationsskoleprojektet.pdf

Green, T.F. (1971). The Activities of Teaching. New York: McGraw-Hill.

Goos, M. (2014). Technology integration in secondary school mathematics: the development of teachers' professional identities. In A. Clark-Wilson, O. Robutti \& N. Sinclair (Eds.), The Mathematics Teacher in the Digital Era. An International Perspective on Technology Focused Professional Development (pp. 139-161). Dordrecht: Springer. doi: 10.1007/978-94-007-4638-1_7

Hanzsek-Brill, M.B. (1997). The relationships among components of elementary teachers mathematics education knowledge and their uses of technology in the mathematics classroom. Unpublished doctoral dissertation. Athens, Georgia: University of Georgia.

Jankvist, U.T. (2015). Changing students' images of "mathematics as a discipline". The Journal of Mathematical Behavior, 38, 41-56. doi: 10.1016/j.jmathb.2015.02.002

Jankvist, U.T., Misfeldt, M. \& Iversen, S.M. (preprint). When students are subject to various teachers' varying policies: A bricolage framework for the case of CAS in teaching.

Kuhs, T. M., \& Ball, D. L. (1986). Approaches to teaching mathematics: mapping the domains of knowledge, skills, and disposition (Research Memo). Lansing, MI: Michigan State University, Center on Teacher Education.

Kvale, S. (1996). Interviews : an introduction to qualitative research interviewing. Thousand Oaks, Calif:: Sage Publications.

Lagrange, J. (2005). Using symbolic calculators to study mathematics: the case of tasks and techniques. The case of tasks and techniques. In D. Guin, K. Ruthven \& L. Trouche (Eds.), The Didactical Challenge of Symbolic Calculators. Turning a Computational Device into a Mathematical Instrument (pp. 113-135). New York: Springer. doi: 10.1007/0-38723435-7_6

Lavicza, Z. (2010). Integrating technology into mathematics teaching at the university level. ZDM, 42(1), 105-119. doi: 10.1007/s11858-009-0225-1 
Leatham, K.R. (2006). Viewing mathematics teachers' beliefs as sensible systems. Journal of Mathematics Teacher Education, 9(1), 91-102. doi: 10.1007/s10857-006-9006-8

Leatham, K.R. (2007). Pre-service secondary mathematics teachers' beliefs about the nature of technology in the classroom. Canadian Journal of Science, Mathematics and Technology, 7(2/3), 183-207. doi: 10.1080/14926150709556726

Leder, G.C. (2015). Foreword. In B. Pepin \& B. Roesken-Winter (Eds.), From Beliefs to Dynamic Affect Systems in Mathematics Education. Exploring a Mosaic of Relationships and Interactions (pp. v-x). Switzerland: Springer. doi: 10.1007/978-3-319-06808-4

Liljedahl, P. (2009). Teachers' insights into the relationship between beliefs and practice. In J. Maaß \& W. Schlöglmann (Eds.), Beliefs and Attitudes in Mathematics Education. New Research Results (pp. 33-44). Rotterdam: Sense Publishers.

McCulloch, A.W. (2011). Affect and graphing calculator use. The Journal of Mathematical Behavior, 30(2), 166-179. doi: 10.1016/j.jmathb.2011.02.002

Nabb, K.A. (2010). CAS as a restructuring tool in mathematics education. Proceedings of the 22nd International Conference on Technology in Collegiate Mathematics. Chicago, IL.

Op't Eynde, P., de Corte, E., \& Verschaffel, L. (2002). Framing students' mathematics-related beliefs. In G. C. Leder, E. Pehkonen, \& G. Törner (Eds.), Beliefs: A hidden variable in mathematics education? (pp. 13-37). Dordrecht: Kluwer Academic Publishers (Chapter 2).

Pajares, M.F. (1992). Teachers' beliefs and educational research: cleaning up a messy construct. Review of Educational Research, 62(3), 307-332. doi: 10.3102/00346543062003307

Partnership For 21st Century Skills (2011). Outcomes for P21 Math Skills Map. Washington, DC: Author. Retrieved from http://www.p21.org/storage/documents/ P21_Math_Map.pdf

Partnership For 21st Century Skills (2004). ICT Literacy Map. Tuczon, Az: Author. Retrieved from http://21ctlearning.pbworks.com/f/ictmap_math.pdf

Philipp, R. A. (2007). Mathematics teachers' beliefs and affect. In F.K. Lester Jr. (Ed.), Second Handbook of Research on Mathematics Teaching and Learning (pp. 257-315). Charlotte, NC: Information Age Publishing.

Rokeach, M. (1960). The open and closed mind. New York: Basic Books.

Schmidt, M.E. (1999). Middle grade teachers' beliefs about calculator use: pre-project and two years later. Focus on Learning Problems in Mathematics, 21(1), 18-34.

Schoenfeld, A.H. (2007). Method. In F.K. Lester, Jr. (Ed.), Second Handbook of Research on Mathematics Teaching and Learning (pp. 69-107). Charlotte, NC: Information Age Publishing.

Skott, J. (2015). Towards a participatory approach to 'beliefs' in mathematics education. In B. Pepin \& B. Roesken-Winter (Eds.), From Beliefs to Dynamic Affect Systems in Mathematics Education. Exploring a Mosaic of Relationships and Interactions (pp. 3-23). Switzerland: Springer. doi: 10.1007/978-3-319-06808-4_1

Swan, M. (2007). The impact of task-based professional development on teachers' practices and beliefs: a design research study. Journal of Mathematics Teacher Education, 10(4), 217-237. doi: 10.1007/s10857-007-9038-8

Tharp, M.L., Fitzsimmons, J.A. \& Ayers, R.L.B. (1997). Negotiating a technological shift: teacher perception of the implementation of graphic calculators. Journal of Computers in Mathematics and Science Teaching, 16(4), 551-575.

Thomas, M.O.J. \& Palmer, J.M. (2014). Teaching with digital technology: obstacles and opportunities. In A. Clark-Wilson, 0. Robutti \& N. Sinclair (Eds.), The Mathematics Teacher in the Digital Era. An International Perspective on Technology Focused Professional Development (pp. 71-89). Dordrecht: Springer. doi: 10.1007/978-94-0074638-1_4

Thompson, A.G. (1992). Teachers' beliefs and conceptions: A synthesis of the research. In D.A. Grouws (Ed.), Handbook of Research on Mathematics Teaching and Learning (pp. 127-146). New York: Macmillan.

Van Zoest, L.R., Jones, G.A., \& Thornton, C.A. (1994). Beliefs about mathematics teaching held by pre-service teachers involved in a first grade mentorship program. Mathematics Education Research Journal, 6(1), 37-55. doi: 10.1007/BF03217261 
Walen, S.B., Williams, S.R. \& Garner, B.E. (2003). Pre-service teachers learning mathematics using calculators: a failure to connect current and future practice. Teaching and Teacher Education, 19(4), 445-462. doi: 10.1016/S0742-051X(03)00028-3

Wilkins, J.L.M \& Brand, B.R. (2004). Change in preservice teachers' beliefs: an evaluation of a mathematics methods course. School Science and Mathematics, 104(5), 226-232. doi: 10.1111/j.1949-8594.2004.tb18245.x

Winsløw, C. (2003). Semiotic and discursive variables in CAS-based didactical engineering. Educational Studies in Mathematics, 52(3), 271-288. doi: 10.1023/A:1024201714126 